\title{
Spreading change of Africa-South America plate: insights from space geodetic observations
}

\author{
Shuanggen Jin $\cdot \mathbf{J}$. Wang
}

Published online: 18 July 2008

(C) Springer-Verlag 2008

Erratum to: Int J Earth Sci (Geol Rundsch)

DOI 10.1007/s00531-007-0220-0

Unfortunately, the acknowledgment part was missing.

It is given below.

Acknowledgments This work was supported by a grant (07KLSGC02) from Cutting-edge Urban DevelopmentKorean Land Spatialization Research Project funded by Ministry of Land, Transport and Maritime Affairs.

The online version of the original article can be found under doi:10.1007/s00531-007-0220-0.

S. Jin $(\square)$

Space Geodesy Research Group,

Korea Astronomy and Space Science Institute,

Daejeon 305-348, South Korea

e-mail: sgjin@kasi.re.kr; sg.jin@yahoo.com

S. Jin · J. Wang

School of Surveying and Spatial Information Systems,

The University of New South Wales,

Sydney, NSW 2052, Australia 